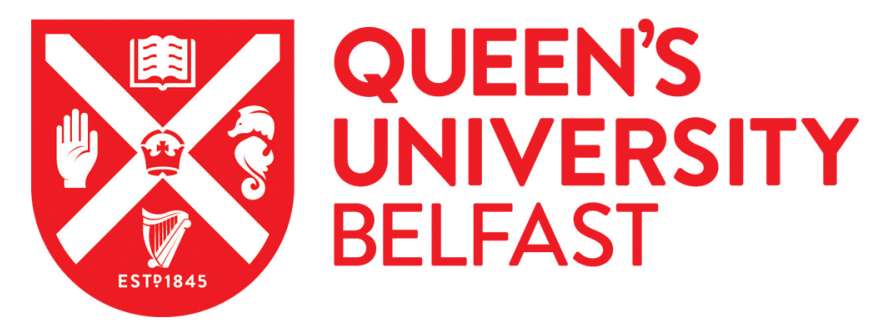

\title{
The Impact of Paid Parental Leave on Labor Supply and Employment Outcomes in Australia
}

Broadway, B., Kalb, G., McVicar, D., \& Martin, B. (2020). The Impact of Paid Parental Leave on Labor Supply and Employment Outcomes in Australia. Feminist Economics. https://doi.org/10.1080/13545701.2020.1718175

\author{
Published in: \\ Feminist Economics
}

Document Version:

Peer reviewed version

Queen's University Belfast - Research Portal:

Link to publication record in Queen's University Belfast Research Portal

Publisher rights

Copyright 2019 Taylor and Francis. This work is made available online in accordance with the publisher's policies. Please refer to any applicable terms of use of the publisher.

\section{General rights}

Copyright for the publications made accessible via the Queen's University Belfast Research Portal is retained by the author(s) and / or other copyright owners and it is a condition of accessing these publications that users recognise and abide by the legal requirements associated with these rights.

Take down policy

The Research Portal is Queen's institutional repository that provides access to Queen's research output. Every effort has been made to ensure that content in the Research Portal does not infringe any person's rights, or applicable UK laws. If you discover content in the Research Portal that you believe breaches copyright or violates any law, please contact openaccess@qub.ac.uk. 


\title{
The Impact of Paid Parental Leave on Labor Supply and
}

\section{Employment Outcomes in Australia}

\author{
Barbara Broadway \\ Melbourne Institute of Applied Economic and Social Research, \\ University of Melbourne, VIC 3010 Melbourne, Australia; and \\ ARC Centre of Excellence for Children and Families over the Life Course
}

Guyonne Kalb*

Melbourne Institute of Applied Economic and Social Research, University of Melbourne, VIC 3010 Melbourne, Australia; ARC Centre of Excellence for Children and Families over the Life Course; and IZA (Bonn)

\author{
Duncan McVicar \\ Queen's Management School \\ Queen's University Belfast \\ Belfast, United Kingdom; and IZA (Bonn) \\ Bill Martin** \\ Institute for Social Science Research \\ University of Queensland \\ Brisbane QLD 4072 Australia
}

February 2019

\footnotetext{
* Correspondence should be directed to Guyonne Kalb; Melbourne Institute of Applied Economic and Social Research; Level 5, FBE Building, 111 Barry Street; University of Melbourne; VIC 3010; Australia; e-mail: g.kalb@unimelb.edu.au; ph: +61 38344 2095; fax: +61 383442111.

** Sadly, Bill Martin passed away in April 2016. This paper would not have been possible without his inspired leadership of the Paid Parental Leave project.
} 


\begin{abstract}
The introduction of the Australian Paid Parental Leave scheme in 2011 provides a rare opportunity to estimate the impacts of publicly-funded paid leave on mothers in the first year post-partum. The almost universal coverage of the scheme coupled with detailed survey data collected specifically for the scheme's evaluation means that eligibility for paid leave under the scheme can be plausibly taken as exogenous following a standard propensity score matching exercise. Consistent with much of the existing literature, we find a positive impact on leave taking in the first half year and on the probability of returning to work in the first year. The paper provides new evidence of a positive impact on continuing in the same job and under the same conditions, where previous conclusions have been mixed. Further, we show that disadvantaged mothers - low income, less educated, without access to employerfunded leave - respond most.
\end{abstract}

Keywords: labor supply, parental leave, Australia

JEL: J13, J18, J22 


\section{Introduction}

Most developed countries, but not the US, provide new mothers with access to universal paid maternity leave. Australia is a recent addition to the group of countries which do so, having introduced an (almost) universal publicly-funded paid parental leave (PPL) scheme in January 2011. This provides us with a rare opportunity to estimate the labor supply and employment impacts of introducing paid parental leave on mothers in the first year following the birth of a child. Given ex ante ambiguity about the labor market impact of paid parental leave schemes on mothers (Uta Schönberg and Johannes Ludsteck, 2014), such evidence is critical if policy makers are to make informed decisions in this space. It is also timely given the planned 2018 introduction of paid parental leave in New York State and widespread calls for a US-wide paid parental leave scheme such as that recently proposed under the Family and Medical Insurance Leave Act ${ }^{1}$.

The literature to date has faced a number of challenges in trying to estimate the impacts of parental leave schemes on leave-taking and other labor market outcomes. First and foremost is the challenge of finding sources of exogenous variation in entitlement to parental leave, given that in many countries paid parental leave is universal and has been in place for many years. Second is the external validity challenge; parental leave schemes display considerable variation across countries - in coverage, duration, balance between paid/unpaid, take-up, generosity, and wider social and institutional contexts. Third, data requirements are demanding, encompassing sufficiently large sample sizes, tracking of individuals throughout the period of interest, explicit observation of eligibility for leave, and ideally a rich set of individual and contextual characteristics, and labor supply and employment outcomes.

\footnotetext{
${ }^{1}$ For details of the proposed Family and Medical Leave Act, introduced in the US Senate in 2015, see https://www.congress.gov/bill/114th-congress/senate-bill/786/text.
} 
In this context, this paper makes two particular and important contributions to the literature. First, the Australian reform is unique amongst recent reforms in other advanced economies in that it introduced - from scratch - paid parental leave of a moderate duration at a moderate payment rate. Evaluation of the Australian reform thus provides crucial information on what policy makers can expect when introducing a moderate duration, universal leave scheme at a basic payment rate in an economy currently without such a scheme, such as many States in the US. If the effects of changes in leave length or generosity are not linear, effects are not necessarily generalizable to other contexts with more extensive, less extensive or (as in the US) no universal leave provisions.

Second, by drawing on rich data collected specifically for this purpose, this paper is able to examine the impacts of a universal paid parental leave scheme on labor market outcomes allowing for heterogeneous impacts across a wide range of mothers' characteristics, such as income and education level, partnering status, type of employment pre-birth, and eligibility for employer-provided paid leave. Thus, we can examine paid leave impacts specifically for a group of women who have limited alternative funding sources for taking time off work (be it other household income, savings, or support from their employer). In general survey data, the number of births observed is typically low, and thus samples are often small even for the full population; detailed analyses of heterogeneous effects across a broad range of characteristics are not typically possible with general survey data. Our study thus highlights the importance of setting funding aside for data collection when a new policy is introduced.

We present estimates of the average impact of the scheme on a range of outcomes. First, we find that after introduction of the PPL scheme, mothers initially delay return to work. The rate of return to work then increases, and once children are about six months of age or older, mothers return to work at a faster rate than a similar cohort of mothers did before the scheme was introduced. . Consistent with much of the existing literature, we also find positive 
impacts on the probability of returning to work within a year, and on returning to the prebirth job or to the pre-birth employer. Turning to our impacts of estimates for mothers with different characteristics, consistent with Maya Rossin-Slater, Christopher Ruhm and Jane Waldfogel (2013), we find that labor market impacts of the PPL scheme are stronger for lower-educated than for higher-educated women. In addition, we find that impacts are stronger for low-income women, for those not eligible for employer-provided paid leave, for self-employed women and for women on casual contracts. This provides support for RossinSlater, Ruhm and Waldfogel's (2013) hypothesis that paid leave schemes are more likely to affect disadvantaged groups of women.

\section{Literature}

Many early papers on the labor supply impacts of parental leave schemes find that leave entitlements have a strong effect on mothers' labor market outcomes. Jane Waldfogel, Yoshio Higuchi and Masahiro Abe (1999) compare mothers' employment in the US, UK and Japan, and find that family leave coverage goes hand in hand with a higher likelihood of pre-birth job retention, potentially improving mothers' labor market outcomes long-term by preserving their skills. Ruhm (1998) finds for Europe that more generous parental leave provisions are associated with increased employment among women, but at reduced wages when the leave period is long. Lawrence Berger and Jane Waldfogel (2004) find that mothers in the US whose employers provide maternity leave coverage exhibit a faster return to work after their paid leave expires than non-eligible women do. Marit Rønsen and Marianne Sundström (2002) find similar results when they look at mothers' employment in Finland, Norway and Sweden: women with a paid leave entitlement have higher employment entry rates following birth than those without, concentrated around the time their leave expires. They conclude that 
maternity leave coverage is generally positive for employment outcomes, but that very long leave entitlements come with a risk of cementing an unequal division of labor in the family. ${ }^{2}$

However, these early papers cannot necessarily be interpreted as causal because they rely on cross-sectional variation in leave entitlement which is unlikely to be exogenous. More recently, a handful of papers with quasi-experimental identification strategies have emerged (see Olivier Joseph, Ariane Pailhé, Isabelle Recotillet and Anne Solaz, 2013; Maya RossinSlater, Christopher Ruhm and Jane Waldfogel, 2013; Rafael Lalive, Analía Schlosser, Andreas Steinhauer and Josef Zweimüller, 2014; Schönberg and Ludsteck, 2014; Gordon Dahl, Katrine Løken, Magne Mogstad and Kari Salvanes, 2016; Charles Baum and Christopher Ruhm, 2016). Maya Rossin-Slater (2017) provides a review. The current paper is able to exploit the introduction of a paid leave scheme in Australia; access to paid leave depends on the timing of birth and can be plausibly taken as exogenous following a standard propensity score matching exercise. Thus, this paper adds to the handful of existing studies internationally that have a credible identification strategy.

While our paper examines the introduction of a short leave period at a moderate payment rate, other papers that exploit far-reaching reforms as a source of exogenous variation evaluate recent European reforms - which typically extended or shortened an existing leave policy that covered several years after birth and often provided high payments. For example, Lalive et al. (2014) base their analysis on an Austrian reform, which involved extending paid leave and job protection from 12 months to 24 months and then reducing it to 18 months. Similarly, Schönberg and Ludsteck (2014) examine a series of five reforms in Germany which involved different length of leave between 6 and 24 months after a 14-week period of

\footnotetext{
${ }^{2}$ Marit Rønsen and Ragni Hege Kitterød (2015) find evidence from Norway that this effect can be counteracted by policies that decrease childcare prices or by family leave arrangement targeted at fathers, while Carmen Castro-García and Maria Pazos-Moran (2016) add that this is only effective if leave for both parents is equally long, non-transferable, and provides a relatively high payment rate.
} 
mandatory leave at the full last salary. Dahl et al. (2016) examine earlier Norwegian reforms that extended paid leave provision from eighteen to thirty-five weeks. Rossin-Slater, Ruhm and Waldfogel (2013) and Baum and Ruhm (2016) examine the impact of the additional six weeks paid leave offered under the California Paid Family Leave scheme introduced in 2004, with almost universal eligibility among private sector workers, at a replacement rate of 55 percent up to a ceiling based on the state's average weekly wage.

Few studies in this recent generation of the literature, however, examine how impacts vary across different groups of mothers. One of the exceptions is the French study by Joseph et al. (2013) which distinguishes the effects of a short additional period (up to six months) of paid leave for low- and high-educated mothers. The study finds larger positive impacts on the probability of being employed after one year, 1.5 years and two years for low-educated mothers. Another exception is Rossin-Slater, Ruhm and Waldfogel. (2013) who also find stronger impacts for less advantaged - less educated, unmarried, non-white - mothers. From this and findings regarding unpaid leave which favor more advantaged women (Wen-Jui Han, Christopher Ruhm and Jane Waldfogel, 2009), Rossin-Slater, Ruhm and Waldfogel (2013) hint at a more general conclusion that extensions to unpaid (paid) leave entitlements may impact more strongly on advantaged (disadvantaged) mothers, respectively. They argue that advantaged mothers are more likely to be eligible for unpaid leave under such policies they have in mind the US Family and Medical Leave Act for which this is likely to be the case - and that advantaged mothers are more likely to be able to afford unpaid time off work. ${ }^{3}$ This is a crucial point for policy makers to consider when thinking about the design of parental leave schemes. However, new evidence on heterogeneous impacts is clearly needed, given the limited number of previous studies and their limitations: there are identification

\footnotetext{
${ }^{3}$ Selective eligibility for employer-provided paid parental leave is also likely to be an issue here, although neither Han, Ruhm and Waldfogel (2009) nor Rossin-Slater, Ruhm and Waldfogel (2013) discuss this.
} 
issues in Han, Ruhm and Waldfogel (2009), and data limitations in Rossin-Slater, Ruhm and Waldfogel (2013) ${ }^{4}$. Moreover, Rossin-Slater, Ruhm and Waldfogel (2013) can also cite only one further study (Pedro Carneiro, Katrine Løken, and Kjell Salvanes, 2010; subsequently published in 2015) in support of their argument. In addition to the small number of studies on heterogeneous reform effects, there are questions over the extent to which their results for one particular reform in one particular context can be generalized across reforms and across countries. Additional evidence on heterogeneous impacts is thus clearly needed.

Our rich data also allows us to analyze a broad range of labor market outcomes. Beyond the more commonly examined outcomes - employment and wages - we also observe mothers' return to the pre-birth job or at least to the pre-birth employer in the first job upon return. Despite the importance of this outcome for retention of human capital, it is less commonly examined in the literature; and where it has been, results have been mixed (for paid leave see: Lalive et al., 2014 and Baum and Ruhm, 2016; for unpaid leave see: Waldfogel, Higuchi and Abe, 1999 and Christopher Baum, 2003).

\section{Institutional Background}

The Australian PPL scheme, introduced on January 1, 2011, aims to extend mothers' time away from paid work following a birth - among other things for maternal and child health reasons - while promoting their attachment to their employer and increasing lifetime attachment to the labor force. The Productivity Commission (2009) states that the objectives of the PPL scheme include improving the health of the mother, the health and development of the child, the rights of children and their place in society, the mother's longer-term attachment to the workplace/workforce, opportunities for fathers to share in childcare and family responsibilities, provision of financial assistance, greater gender equity in the home

\footnotetext{
${ }^{4}$ See Baum and Ruhm (2016) on this point.
} 
and in the workplace, promoting balance between paid work and family life, and enhancing the fertility of the population. Evaluating the scheme's success against all these objectives is beyond the scope of this paper, which focuses on mothers' attachment to the workplace/workforce, and promoting balance between paid work and family life.

Prior to 2011 there was no publicly-funded paid parental leave scheme in Australia. Each parent had a job-guarantee right to unpaid leave for up to one year if they had worked for their employer for at least twelve months prior to the birth (and each parent's entitlement could be transferred to the other parent, subject to employer approval). Paid leave, however, was only available if it was provided by the employer - as a company policy, or as the result of collective or individual negotiations between employer and employee. Not all organizations provide paid leave to their employees, and those that do, do not necessarily cover all employees. Coverage varies by industry, employer size, contract type, and with the employee's education and skill level.

Since 2011, PPL pays the primary carer of a newborn child - usually the mother - up to eighteen weeks at a flat rate corresponding to the Australian National Minimum Wage equal to $\mathrm{A} \$ 656.90$ ( $\mathrm{US} \$ 480$ ) per week at the time of writing. The payments, which are taxable, may be claimed at any time within the first twelve months following the birth, but must be taken in one continuous period. Eligibility for the scheme is almost universal: mothers are required to have worked for at least 330 hours and for at least ten months (with gaps of less than eight weeks between consecutive working days counting towards the ten months) over the thirteen-month period prior to the expected date of birth, with an individual adjusted taxable income of $\mathrm{A} \$ 150,000$ or less in the financial year before the birth; and to be a permanent resident or citizen in Australia. Once a mother returns to work she becomes ineligible, although any remaining payment may be transferable to an eligible partner if they become the primary carer. Although publicly funded, PPL is provided through employers in 
the majority of cases, and there are further associated measures designed to encourage mothers and employers to keep in touch during the leave period and to support activities that facilitate the mother's return to work. PPL is paid in full on top of any entitlement to employer-provided paid leave the mother may be eligible for, regardless of that payment's duration and level of payment. We examine whether there is heterogeneity in the behavioral response to PPL, for women with and without access to employer-provided leave.

In our post-PPL survey, awareness of the new payment is near universal (99.1 percent), and 83.7 percent of mothers have taken up the payment (Martin et al., 2014). However, this sample only includes mothers who meet the criteria for eligibility, and it is possible that awareness of the payment is lower among those who are not eligible for it. For more detail on the PPL scheme see Martin et al. (2015).

The introduction of PPL follows several decades of rapid growth in women's participation in paid employment and education in Australia. The overall female labor force participation rate has increased from 34 percent in 1961 to 59 percent in 2011 (Australian Bureau of Statistics (ABS) 2011a), primarily through increased employment of mothers. Between 1991 and 2011, the proportion of mothers in families with children under 18 who were employed rose from 55 percent to 65 percent (Jennifer Baxter 2013). Women are now more likely to attain postschool qualifications than men, with 41 percent of women aged 25 to 29 years having university degrees in 2011, compared to 30 percent of men (ABS 2012).

Despite this growth, Australia has amongst the lowest levels of labor force participation in the Organisation for Economic Cooperation and Development (OECD) countries for women of prime childbearing age. In 2013, the labor force participation rate of women aged 25 to 34 years in Australia was 74.4 percent, similar to that of the US (73.5 percent) and the UK (77.6 percent), but well behind Canada (81.5 percent), France (81.7 percent), Germany (79.7 
percent), the Netherlands (85.2 percent), Spain ( 86.0 percent) and Sweden ( 84.0 percent). ${ }^{5}$ In general, the countries with higher maternal participation rates tend to be those where parents have access to well-developed paid parental leave schemes complemented with extensive, affordable childcare (Florence Jaumotte, 2003). Guyonne Kalb and Thor Thoresen (2010) specifically compare Australia before paid parental leave was introduced with Norway, finding a gap in labor force participation of 20 percentage points for women with children aged one to four, but no gap for women without children. Of course, the apparent crosscountry association between access to paid parental leave and maternal participation rates does not necessarily imply a causal relationship from one to the other. That is where detailed micro data either side of a major reform - in this case the introduction of PPL - comes in particularly useful.

At the time of introduction of PPL, data from the Household Income and Labour Dynamics in Australia (HILDA) survey show that an estimated 56.8 percent of employed women aged 20 to 45 in Australia had access to paid parental leave provided by their employer. However, this was not distributed evenly across all women, but concentrated amongst those with fixed-term or permanent work (around 72 percent compared to 19.1 percent in casual work ${ }^{6}$ ), those on above-median wages (71.3 percent compared to 37.8 percent for those on below-median wages), those in full-time employment (65.7 percent compared to 41.2 percent in part-time work), those with higher education (77.5 percent for those with a university degree compared

\footnotetext{
${ }^{5}$ Source: https://stats.oecd.org/Index.aspx?DataSetCode=LFS_SEXAGE_I_R. Accessed on 22 August 2017.

${ }^{6}$ The term 'casual employment' is understood differently in Australia compared to many other countries (where 'casual employment' is typically associated with irregular working hours and no expectation of continued employment). In Australia, so-called casual employment is often of long duration, and working hours and earnings may or may not be steady over time. Instead, it is commonly understood that casual employees are those who are not entitled to paid annual leave and paid sick leave; this is also the definition used in surveys collected by the Australian Bureau of Statistics (Hielke Buddelmeyer, Mark Wooden and Susan Ghantous 2006). In contrast, permanent and fixed-term contracts provide paid leave entitlements, with fixed-term contracts having a specified end date for the employment contract and permanent contracts having no specified end date. The survey used in this study asks respondents to self-identify as being employed on a i) permanent basis, ii) fixed-term basis, iii) casual basis, or iv) other.
} 
to 39.8 percent for those with less than a high-school certificate), and those in professional occupations (76.5 percent compared to 32.9 percent for laborers). Overall, more advantaged women were more likely to have access to employer-funded paid parental leave than less advantaged women.

\section{Data and descriptive statistics}

This paper exploits two surveys specifically designed for the evaluation of Australia's PPL. The first survey collects data after the policy was announced but before it took effect; data were collected for a cohort of mothers who had given birth before the announcement. About one year later, data were collected for a second cohort of mothers who had given birth well after the policy was introduced.

The timeline of the introduction of the policy and data collection was as follows:

October/November 2009

March 2010

July 2010

December 2010/January 2011

January 2011

October/November 2011

April/May 2012

October/November 2012
First cohort of mothers gives birth

Policy is announced to take effect at the start of the following year Survey design begins

First cohort of mothers is interviewed

Policy takes effect

Second cohort of mothers gives birth

Second cohort of mothers is interviewed (Wave 1)

Second cohort of mothers is interviewed (Wave 2)

The first survey with information on mothers before PPL was introduced is named the

Baseline Mothers Survey (BaMS) which surveyed a sample of mothers who gave birth in

October or November 2009. Survey participants were selected so that all mothers fulfilled the criteria for eligibility and thus would have been eligible for PPL had it existed at the time.

Interviews were held around 13 to 14 months after birth. The second survey with information on mothers who gave birth after PPL was introduced is the longitudinal Family and Work Cohort Study (FaWCS) which surveyed a sample of mothers who gave birth in October or 
November 2011. Only women who were eligible for PPL were included in the survey. The FaWCS survey was conducted in two waves: wave 1 when the babies were about six months old and wave 2 when the babies were just under 13 months old.

A set of four survey questions provides information on relevant labor market outcomes. Respondents are asked i) whether they have had a paid job at any time since their child was born; if yes, they are asked ii) how old their child was when they first worked in a paid job after birth (in weeks or months). From these questions, we construct the duration until return to work; mothers are censored at the last interview date if they did not return to a job by then. Those who have had any paid job(s) since birth are asked about the first of their jobs: iii) whether it was the same job (position and employer) as they had before their child was born or not, and if it was, iv) whether their salary, working hours, work duties or conditions changed. Outcomes before and after the introduction of PPL are shown in Table 1.

$<$ Table 1 about here >

After PPL was introduced, mothers in our sample are less likely to return before 18 weeks after birth (when PPL ends) and more likely to return shortly after 18 weeks and before half a year after birth. In the post-PPL-cohort, mothers are more frequently observed to have returned to the same job and job conditions, and less often to have changed positions or employers. On the other hand, post-PPL mothers are less often observed to return to work at all, although this is likely to reflect differences in the timing of the interview rather than a difference in behavior.

The surveys were designed to collect the same information on comparable women. In practice the group of surveyed mothers with access to PPL (post-PPL) and the group of mothers without access (pre-PPL) are similar along many observed dimensions - as we would expect given access is determined solely by the timing of birth within a fairly narrow 
window - but differ in some others (see Table 2). Some differences reflect the different implementation of the pre- and post-PPL surveys. Specifically, post-PPL mothers were interviewed when their child was on average nearly 13 months old, compared to nearly 14 months in the cohort prior to introduction of PPL. As a result, almost one in five mothers in the post-PPL cohort was interviewed before her child's first birthday, while this was the case for only one in a hundred mothers in the pre-PPL cohort. Post-PPL and Pre-PPL mothers were of about the same age on average at the time they gave birth, ${ }^{7}$ had similar education levels, were equally likely to have a partner and equally likely to have other children already. ${ }^{8}$ There are some minor differences between the two cohorts: Post-PPL mothers are three percentage points less likely to be born in Australia and four percentage points more likely to speak a language other than English at home and their partners are slightly more likely to have a tertiary education, but a slightly lower occupational prestige. ${ }^{9}$

\section{$<$ Table 2 about here >}

There are also some differences in the types of jobs the mothers held before birth (see Table 3). Compared to pre-PPL mothers, post-PPL mothers were slightly more likely to work in the private sector; were more likely to work in medium-sized firms (21-100 employees) rather than large firms (>100 employees); were slightly less likely to report receiving support from their employer during pregnancy; worked slightly longer hours but for lower annual earnings

\footnotetext{
${ }^{7}$ Age at birth was not asked directly but derived from information on the mothers' age at time of the interview (recorded in full years) minus the child's age at the time of interview (recorded in days); it is thus subject to some minor measurement error.

${ }^{8}$ The number of other children in the household is not recorded at the time of the study child's birth, but at the time of the interview. To provide a better approximation of the number of children at the time of birth, we disregard any other children who were less than one year old at the time of interview. This affected three families in the post-PPL cohort and 16 families in the pre-PPL-cohort. These are likely to be children who were born after the study child.

${ }^{9}$ The Australian Socioeconomic Index 2006 (AUSEI06) assigns a 'status score' to each occupation coded according to the Australian and New Zealand Standard Classification of Occupations (ANZSCO). The scale is a continuous measure that ranges from 0 to 100 .
} 
(the latter not statistically significant); with a slightly different distribution across industries, but no difference in the proportion working in female-dominated industries. ${ }^{10}$

$<$ Table 3 about here>

Such compositional differences between the pre- and post-PPL samples could themselves lead to differences in post-birth labor market outcomes. Under standard assumptions, however, the method set out in the following section allows us to separate the impact of PPL from the impact of these small compositional differences.

\section{Methodology}

This paper considers two sets of outcomes: first, the duration until mothers return to work, and second, employer and job characteristics upon first return to work. Estimations follow standard procedures for the outcomes in question as described in Section 5.1. The impact of PPL on these outcomes is estimated by comparing outcomes for mothers who gave birth before the introduction of PPL with outcomes for mothers who gave birth after introduction of PPL. There are slight differences between both groups in observable characteristics, and possibly in unobservable characteristics above and beyond the difference in the timing of birth before or after the introduction of PPL. To deal with these differences, we apply propensity score matching (PSM) under the standard assumption of conditional independence as described in Section 5.2. Nevertheless, some unobservable differences that potentially violate this assumption may be present. Potential implications for validity of our estimates, as well as the direction of potential biases, are discussed in Section 5.3.

\footnotetext{
${ }^{10}$ We define an industry as female-dominated, if more than 50 percent of the employed persons in that industry are female regardless of full-time or part-time status. We used Table Builder Basic to retrieve that information from the 2011 Census (Australian Bureau of Statistics 2011b). Female-dominated industries are i) retail trade, ii) accommodation and food services, iii) financial and insurance services, iv) rental hiring and real estate services, v) administrative and support services, vi) education and training and vii) health care and social assistance.
} 


\subsection{Outcomes of interest}

We analyze the impact of PPL on the duration until return to work using a survival analysis (event history) approach. At the interview, mothers are asked the exact time when they first returned to work after childbirth. Information from each mother is used up to the date of her interview, i.e. until the last day that we have information on her work status. We allow the hazard rate and, crucially, the PPL impact on the hazard rate to vary over time. We use two alternative hazard rate estimators. First is the non-parametric Kaplan-Meier (KM) estimator $K M_{t=x}=\frac{\sum \text { Mothers who return to work on day } x}{\sum \text { Mothers who did not return to work before day } x}$, which is computed separately for mothers who did and mothers who did not have access to PPL (we will apply weights from a matching procedure discussed below).

Secondly, we estimate the hazard rate as a proportional Cox model. ${ }^{11}$

$$
h_{t=x}=h_{0}(x) \cdot \exp \left(\beta_{1} \cdot P P L+\beta_{2} \cdot P P L \cdot x\right)
$$

where $h_{0}(x)$ is the baseline hazard varying with duration since birth $x, P P L$ is an indicator that takes the value one if a mother had access to PPL and zero otherwise, and $\beta_{1}$ and $\beta_{2}$ are parameters to be estimated. ${ }^{12}$ The reform's desired impact is to encourage mothers to stay at home in the first few months after birth, but also to encourage their return to work later so that they catch up to (and possibly overtake) mothers who had no access to PPL. In the Cox model, this corresponds to a negative $\beta_{1}$ and positive $\beta_{2}$; in the $\mathrm{KM}$ estimates, this corresponds to a survivor function for post-PPL mothers that is higher than that for pre-PPL

\footnotetext{
${ }^{11}$ The main advantage of the Cox estimate over the KM estimate is that the former provides us with a hypothesis over the signs of two parameters that is easily testable and makes the effect of PPL easy to interpret. However, the KM-estimator is more flexible in how the impact of PPL is allowed to vary with the time that has passed since birth, as no functional form for the hazard rate is imposed.

${ }^{12} \mathrm{We}$ also estimate a version of the model that includes an additional quadratic effect of PPL, and a version with only the constant impact of PPL, $\beta_{1}$.
} 
mothers immediately after birth, but decreases faster at some later point until both functions eventually intersect.

For the analysis of employer and job characteristics upon first return to work, we consider mothers who have returned to work by their child's first birthday, and assess the impact of PPL on whether these mothers return to the same employer and whether they return to the same conditions (working hours, annual pay etc.) as in their pre-birth job. Using our matching framework discussed in the following subsection, we can simply compare sample means for both outcomes for mothers with access to PPL, with the weighted sample means for the matched mothers without access to PPL.

As mentioned in Section 4, censoring is slightly more common in the post-PPL cohort (32 percent) than in the pre-PPL cohort (30 percent) (see Table 1). One source of this small difference is panel attrition: 17 percent of post-PPL mothers drop out of the survey between wave 1 and wave 2, while pre-PPL mothers are interviewed only once, so panel attrition cannot occur for them. In addition, post-PPL mothers were slightly more likely to be interviewed early (i.e., within one year from childbirth) than pre-PPL mothers. We test how this affects our results by performing this part of the analysis on the full sample of mothers who were observed to have returned to work before their child's first birthday, and on the uncensored sample of mothers who were observed to have returned to work before their child's first birthday and who were interviewed on or after the child's first birthday.

Finally, the analyses described above are performed separately for different subgroups to gain insight into which mothers respond most or least strongly to the PPL scheme. This allows us to test Rossin-Slater, Ruhm and Waldfogel's (2013) hypothesis that extensions to paid leave entitlements may impact more strongly on disadvantaged mothers. We expect mothers with 
low income, with lower education, without employer-provided leave, in casual employment, in self-employment, and finally single mothers to respond more strongly to the new policy.

\subsection{Propensity score matching}

We use a PSM approach to identify PPL impacts separately from compositional differences between post-PPL and pre-PPL mothers, under a standard conditional independence assumption (Paul Rosenbaum and Donald Rubin, 1983). Specifically, we estimate a probit model for treatment status (access to PPL) regressed on all other relevant observed characteristics - those listed in Tables 2 and 3 - as explanatory variables. ${ }^{13}$ Matching mothers who gave birth pre-PPL to mothers with comparable characteristics who gave birth post-PPL, and evaluating differences in both groups' labor market outcomes yields our estimate of PPL's impact on treated mothers' labor market outcomes (the average treatment effect on the treated). ${ }^{14}$

The distribution of propensity scores of having access to PPL by survey cohort is shown in Figure $1 .{ }^{15}$ The distributions for both cohorts cover about the same range. ${ }^{16}$ Only for propensity scores of 0.9 and higher are there a sizable number of treated individuals, but almost no untreated individuals who could be used as possible matching partners with similarly high propensity scores. These treated mothers are considered 'off support'. Thus,

\footnotetext{
${ }^{13}$ Not included in the matching are the child's age at time of the interview and the indicator for femaledominated industry (since the finer measurement of industry is included). Income is included in 2012 \$A only. ${ }^{14}$ The interpretation as 'average treatment effect' in this context holds only if we interpret having access to PPL as a treatment. However, if we interpret taking PPL as the treatment, introducing access to PPL in January 2011 is called the 'intention to treat', and the procedure described above yields the so-called 'intention-to-treat effect' (ITT). From a policy perspective this ITT effect is the more interesting result since the non-use is not due to a lack of information or other hurdles preventing parents from accessing PPL; it is a conscious choice.

${ }^{15}$ Figure 1 shows the distribution of propensity scores for the full set of mothers; this is the sample we use for the analysis of the duration of return to work. The analysis of the job characteristics upon return relies on the subset of mothers who have returned to work, and another subset of mothers is used for those who have returned and changed some of their job characteristics. Figures analogous to Figure 1 for these two subsets are shown in Appendix A.1.

${ }^{16}$ Note that any 'untreated individual' can be a matching partner for several different 'treated' individuals.
} 
we exclude the 5 percent of treated individuals with the highest propensity scores from the analysis. ${ }^{17}$ They are represented by the black bars; the white bars show the remainder of the sample of treated mothers who are 'on support' and are used for the analysis.

< Figure 1 about here >

To match mothers with and without access to PPL, we apply kernel matching with a bandwidth (maximum acceptable difference between the treated individual's propensity score and her potential match's propensity score) of 0.1 . We tested smaller and larger bandwidths. Increasing the bandwidth beyond 0.1 rapidly decreases the matching quality as measured by i) the joint correlation of socioeconomic characteristics with the treatment status (which should not be statistically different from zero after the matching) and ii) the average bias after matching (which should be as small as possible). Decreasing the bandwidth to lower values does not increase the matching quality any further, but decreases the sample size. We thus chose 0.1 as the optimal kernel bandwidth. ${ }^{18}$ Appendix A.2 contains further detail on the matching quality with different bandwidths, illustrating the reasoning for the choice of 0.1 . Higher weights are assigned to close matches than to more distant matches.

After the matching procedure, only two statistically significant, but trivial, differences of one percentage point remain between pre-PPL and post-PPL mothers (i.e. working in 'Professional, Scientific and Technical' and in 'Administrative Support and Services'). Rubin's B (as defined in Paul Rosenbaum and Donald Rubin, 1985) is only 5 percent in both cases. Appendix A.3 reports all matched characteristics for both groups of mothers in detail. ${ }^{19}$

\footnotetext{
${ }^{17}$ However, a sensitivity analysis with the 'off support' mothers included does not change the results. They are presented in Appendix A2.

${ }^{18}$ Sensitivity tests with alternative approaches are carried out. Nearest neighbor matching with one, two and five neighbors, and radius caliper matching with caliper values of $0.1,1,5$ and 10 percent are applied. All point estimates remain very similar. The results are presented in Appendix A.2.

${ }^{19}$ For the full sample, the matching quality is shown in Table A.2. For the analysis of job characteristics upon return to work, the sample is restricted to include only those mothers who actually returned to work. The
} 
Thus, the matching quality is very high; ensuring that the estimated impact of the PPL scheme on labor market outcomes is not biased by differences in observable characteristics. As with all such studies, the crucial assumption is of course that the matched samples do not differ in relevant unobserved characteristics.

\subsection{Threats to identification from unobserved sources}

In the absence of a control group, comparing labor market outcomes of pre-PPL mothers and post-PPL mothers could lead to a biased estimate of the effect of PPL caused, for example, by changes in the economic environment over time or by selection processes into eligibility for PPL. We discuss four potential threats to the validity of the estimates in sections 5.3.1 to 5.3.4 below, followed by a brief summary in 5.3.5.

\subsubsection{Childcare costs}

A potentially important contextual difference concerns childcare. Childcare prices were increasing by much more than inflation, over 17 percent from December 2010 to December 2012 (ABS, 2013b). This may have had a dampening effect on women returning to work. We cannot rule out that this remains an important unobserved difference between the pre- and post-PPL samples, even after the matching procedure outlined before. It is plausible that high childcare costs decrease a mother's probability of returning to work, which would lead to post-PPL mothers' survivor function decreasing at a slower rate than that of pre-PPL mothers, even if PPL has no effect on mothers' return to work. If PPL works as intended i.e., it initially decreases, then increases mothers' probability of returning to work - our analysis might thus overstate the policy's initial slow-down-effect, and understate its effect

propensity score is re-estimated for the restricted sample and the same matching procedure is applied afterwards. The matching quality for the sub-sample of returned mothers is reported in Table A.3 of Appendix A.3. Similarly, for the analysis by sub-groups, the matching procedure is applied after restricting the sample to the sub-group in question, which is equivalent to exact matching on the group indicator, combined with propensity score matching on all other characteristics. 
on later returns. We would expect the latter bias to be more relevant than the former, assuming that labor supply is less responsive to childcare costs in the first few months after birth than it is later on in the longer term.

However, if this mechanism is important, we would expect to see differences across the prePPL cohort and post-PPL cohort when it comes to changes in the average job conditions upon return to work. For example, if some mothers in the post-PPL cohort do not return to work because of increased childcare costs, and this is not the case in the pre-PPL cohort, we would expect that those mothers in the post-PPL cohort who do return will accept a lower pay-cut than their pre-PPL counterparts did. While PPL provides incentives to retain the pre-birth job, the policy has no plausible direct impact on what pay to accept upon return. We can thus explore whether different childcare costs introduce a substantial bias to our estimates of the effect of PPL by comparing differences in both cohorts' outcomes that should be affected by a 'childcare bias' but not by PPL. We test whether pre-PPL mothers and post-PPL mothers differ in absolute and relative pay-cut relative to their pre-birth job, or in their probability of accepting a decrease in occupational prestige or less favorable contract types.

\subsubsection{Aftermath of the Global Financial Crisis}

Another contextual difference for mothers of both cohorts may be caused by differences in the labor market situation. Compared to other countries, the Global Financial Crisis had a limited and short-lived effect on the labor market in Australia. Comparing ABS key statistics on the labor market situation around the time when the children in the two samples turned one year of age, suggests that the labor market situation is very similar in the two periods. Unemployment is only slightly higher in the pre-PPL period than in the post-PPL period (5.2 percent vs. 5.0 percent), while the employment rate amongst women aged 15-64 years was the same at 66.5 percent (ABS, 2013a). Both cohorts also experienced a labor market with near identical earnings growth over the first year after they gave birth: ordinary full-time 
earnings increased by 4.6 percent from November 2009 to November 2010, and by 4.8 percent from November 2011 to November 2012 (ABS, 2015). Nonetheless, we cannot completely rule out that, compared to post-PPL mothers, pre-PPL mothers had to decide regarding their return to work in a slightly less favorable labor market. If this is the case, it would have been particularly relevant in the first few months after birth when the Global Financial Crisis might still have had some effect. This could have slowed down the return to work immediately after birth for pre-PPL mothers relative to post-PPL mothers. If PPL indeed works as intended and causes mothers to delay their return to work initially - before speeding it up later on - our analysis might thus slightly under-estimate such an initial slowdown: i.e., any estimated initial slow-down would represent a lower bound of the true effect.

\subsubsection{Effects of PPL on labor supply before subsequent births}

The introduction of PPL might increase mothers' labor supply not only by strengthening ties with the employer, but also by giving an incentive to fulfil labor supply criteria in order to become eligible for PPL for future childbirth. After the announcement of PPL, this incentive was in place not only for post-PPL mothers, but also for pre-PPL mothers. Comparing the labor supply of both groups thus may not show the policy's full effect. This potential bias could play a role from March 2010, i.e. when pre-PPL mothers' babies were about five to six months old. ${ }^{20}$ If PPL works as intended and increases mother's labor supply a few months after birth, our analysis will thus yield a lower-bound of this effect.

\subsubsection{Selection into motherhood}

If the introduction of PPL induces changes in fertility, then pre-PPL mothers may have different mean characteristics compared to mothers after the introduction of PPL. Comparing

\footnotetext{
20 This is because mothers can receive PPL for children born on 1 January 2011 at the earliest, and must have had some employment in the ten months before that; that is, from 1 March 2010 onwards. The date from which employment histories could be relevant for future eligibility also coincides with the announcement of the policy.
} 
mothers' characteristics before and after PPL in Table 2, the two groups appear similar, except for some small differences that can be controlled for using the PSM approach. This finding is supported by Micaela Bassford and Hayley Fisher (2016) who conclude that PPL had no impact on fertility intentions at the extensive margin, and only a small effect at the intensive margin, increasing the number of intended children by 0.28 if at least one child was desired already. However, even this small effect on the desired number of children was observed for childless women only, and disappeared completely once the women actually had a child. This seems unlikely to lead to a major change in selection into actual motherhood.

\subsubsection{Discussion of the potential biases}

Assuming that the policy works as intended (i.e., it initially slows mothers' return to work down, then speeds it up), two of these potential biases (the financial crisis and the pre-birth labor supply effects) imply that our analysis potentially understates one of those effects, while not affecting the other. That means that overall our estimates yield a lower bound of the policy's behavioral impact. A third potential bias (childcare costs) would lead to a negative bias of the effect of PPL on mothers' hazard rates of return to work: the analysis would overstate the initial slow-down and understate the speeding up later on. However, if this bias is important at all, the latter effect should be more relevant than the former, again leading us to conclude that our estimates - while not necessarily unbiased - represent a lower bound for the policy's true behavioral impact. Moreover, we can explore the importance of this bias and show whether it plays a role empirically. While the direction of the fourth potential bias (selection into motherhood) is ambiguous, it appears unlikely to play a large role given existing evidence on the lack of fertility responses to the introduction of PPL. 


\section{Results}

\subsection{The impact of PPL on the duration until return to work after birth}

The estimated KM survivor functions for not yet having returned to work are shown in Figure $2 .{ }^{21}$ The solid (red) line represents the survivor function of mothers who had access to PPL; the dashed (blue) line is the survivor function for the sample of matching partners who did not have access. The statistical significance level of the gap between the two at different durations is shown in an accompanying table (Table 4). The divergence between the two lines in the first five to six months of the child's life shows how PPL initially delays the return to work, especially in the first three months. In the second three months the proportion of postPPL mothers who have returned to work starts to catch up with that of the pre-PPL mothers. By six months the mothers with access to PPL have caught up, with just under 40 percent of both groups having returned (and just over 60 percent not yet returned). The average number of extra leave days taken within this period is 7.2 days. Beyond six months, mothers with access to PPL are more likely to return to work. By the end of one year, the average number of additional leave days taken is down to three. Qualitatively speaking, this pattern of results is precisely the desired effect of the policy.

\section{< Figure 2 about here> \\ $<$ Table 4 about here >}

Of the 131,307 women who received PPL between January 2012 and December 2012, around 10,000 mothers, who otherwise would have returned to work already, were still at home up to four months after birth. This number drops in the second half of the year when post-PPL mothers begin to return to work more quickly, and it turns into an increase in the number of

\footnotetext{
${ }^{21}$ The survivor function based on estimation without applying the propensity score matching approach, showing a very similar pattern, is provided in Appendix A.4.
} 
women who have returned to work at a specific point in time. After one year, our estimates imply that just under 7,000 mothers are back at work who would otherwise still be at home. By improving mothers' opportunities to stay at home immediately after the birth, while simultaneously making a return to work more likely later on, the scheme makes a clear contribution to a better balance between paid work and family life - one of the policy's explicit goals.

The KM result is echoed by our estimation of the semi-parametric Cox model (see Table 5). ${ }^{22}$ We estimate three different specifications of the Cox model. Our preferred model as described in Section 5.1 includes a constant effect of PPL (which measures how the PPL scheme affects the hazard rate on the day of birth) and a linear effect (which measures how the impact of PPL changes as the new-born child ages), and best balances flexibility with ease of interpretation. The results show that the hazard rate of return to work on the first day of birth if the mother has access to PPL is only $\exp (-0.287)=75.05$ percent of the corresponding (already very low) hazard rate if the mother does not have access to PPL. With every day that elapses after birth, however, the hazard rate for PPL mothers increases by 0.18 percent more each day than the hazard rate of mothers without access to PPL. When the baby is 160 days old the hazard rates of mothers in the two groups are equal $(0.7505 \times$ $\left.1.0018^{160}=1\right)$, i.e. the mothers with access to PPL catch up to those without access to PPL five to six months after birth. The coefficients of the constant and the linear effect are both significant at the 0.1 percent-level. The quadratic specification gives a similar pattern of results. ${ }^{23}$ As suggested by the KM survivor functions, the introduction of PPL initially slows down the return to work, and then speeds it up.

\footnotetext{
22 The equivalent estimates without matching are given in Appendix A.4.

${ }^{23}$ The simplest model, restricting the impact of PPL to be duration-invariant, gives very different and misleading results, because the initial negative and eventual positive impacts, which are likely to continue beyond the first year, approximately average out within the first year after birth.
} 
$<$ Table 5 about here >

These results are similar to those found for leave schemes in other Western countries in many earlier studies. For example, Baum (2003) found that entitlement for twelve weeks of (unpaid) maternity leave in the US increased the probability of a return to work within one year by three to four percentage points, but slowed down the return to work in the first two months after birth. Likewise, Berger and Waldfogel (2004) found a delay in return to work when US mothers have access to paid or unpaid leave, but the return-to-work rate increased after the maximum leave entitlement ends, with a positive net effect. Rønsen and Sundström (2002) found the same for paid leave entitlements in Sweden, Norway and Finland. The net effect (of the increased and decreased rate of return) is positive overall if the leave does not exceed seven months in Finland and just over one year in Sweden. Baum and Ruhm (2016) find a similar pattern of initially delayed return to work followed by catching up for the California Paid Family Leave scheme. For Australia, Barbara Hanel (2013) analyzed employer-paid parental leave and found that women who are eligible for paid parental leave delay their return to work from the first to the second half of the first year after birth. Jennifer Baxter (2009) presents similar results.

We next consider whether PPL impacts heterogeneously on the leave taking of mothers according to their socio-demographic and pre-birth job characteristics. Figure 3 presents KM survivor functions estimated separately for different groups: mothers with high income and mothers with low income (upper versus lower tercile of the income distribution); mothers with and without a tertiary qualification; mothers with and without employer-provided leave; mothers in casual employment and mothers in permanent or other non-casual employment; employed versus self-employed mothers; and finally, mothers with and without a partner at 
the time of birth. The corresponding coefficients from the linear Cox model are presented in Appendix A.5.

\section{$<$ Figure 3 about here >}

This estimation by subgroup makes clear that the biggest behavioral response to PPL is to be found among relatively disadvantaged mothers, i.e. those with low income, those without tertiary qualifications, and those without employer-provided paid leave. This is in line with findings for France by Joseph et al. (2013) and for California by Rossin-Slater, Ruhm and Waldfogel (2013). It is also in line with Rossin-Slater, Ruhm and Waldfogel's more general hypothesis that paid leave schemes are more likely to affect disadvantaged groups of women. In the PPL case the intuition is straightforward; a flat-rate payment of 18 weeks at minimum wage corresponds to a low wage replacement rate for high-income mothers (who are more likely to be educated to tertiary level) and vice versa, i.e. the reduction in opportunity costs for delaying return to work is larger for low-income mothers when they gain access to PPL than for high-income mothers. The same intuition applies to differential PPL impacts by access to employer-provided parental leave, which is in any case disproportionately offered to high-income mothers (e.g. Human Rights and Equal Opportunity Commission, 2002). ${ }^{24} \mathrm{~A}$ lack of access to employer-provided leave may also partly explain the very substantial PPL impact on self-employed mothers, for whom both the initial negative impact and the positive 'catch-up' impact of PPL on the return to work hazard are particularly large. Mothers who were on a casual contract before birth display a slightly larger response to the introduction of

\footnotetext{
${ }^{24}$ In order to see whether the main source of disadvantage in this context is mothers' low income or the lack of access to employer-paid leave, we repeated the analysis comparing four groups: low-income and high-income mothers, each with and without access to employer-paid leave. It appears that the initial slow-down in mother's return to work is driven primarily (although not exclusively) by low-income status (i.e. with PPL these women can now afford longer leave), while the increased return to work later on is primarily (but not exclusively) driven by a lack of access to employer-paid leave (i.e. with PPL there appears to be a stronger connection to the employer). The results are presented in Appendix A.5.
} 
PPL compared to those on other forms of employment contract. However, the impact is not as large as for some of the above-mentioned groups of mothers.

A somewhat different picture emerges for single mothers versus partnered mothers. ${ }^{25}$ Since 95 percent of all mothers had a partner at birth, the results for mothers with a partner are very similar to the results for the entire sample. For single mothers, however, the proportion not yet returned to work decreases substantially slower than for partnered mothers beyond six months, which might reflect problems with regard to obtaining childcare, other institutional factors (e.g. welfare eligibility), selection into single motherhood, or some combination of the above. Nevertheless, single mothers' response to the introduction of PPL is similar to that of partnered mothers, although the positive impact on eventual return to work appears larger in magnitude for single mothers (with the caveat that none of the effects are statistically significant given the small number of single mothers in the sample).

\subsection{The impact of PPL on job characteristics after birth}

One of the aims of the PPL scheme is to improve retention rates for mothers in their current (i.e. pre-birth) jobs, in part to ameliorate any loss in human capital experienced following the birth of a child. Employers were responsible for administering PPL payments partly to achieve better job continuity. Table 6 shows that not only does PPL improve the probability of returning to work by one year after childbirth, but conditionally on having returned, PPL also has a positive impact on the same-job retention rate (same employer and position). ${ }^{26}$ Of the mothers who returned to work within 365 days after the baby's birth, 78 percent of mothers with access to PPL returned to the same job compared to 74 percent of mothers

\footnotetext{
${ }^{25}$ Single mothers are defined here as those not living with a partner at the time they gave birth. Although a few of these mothers had partners (who they were not living with), the vast majority did not have a partner.

${ }^{26}$ The job under consideration is the first job upon return after childbirth.
} 
without access to PPL. ${ }^{27,} 28$ Not all studies cited earlier in this paper examine the probability of returning to the same job, and where they do, the evidence is somewhat mixed. For paid leave, Baum and Ruhm (2016) find either no effect or a positive effect (of a roughly similar magnitude to our estimate) depending on the extent to which the sample is restricted to mothers who work for more weeks during pregnancy. Lalive et al. (2014) find either no impact or a small negative impact depending on the precise nature of the reform - covering both paid and unpaid leave - in question. Both Waldfogel, Higuchi and Abe (1999) and Baum (2003) find positive impacts (broadly in line with the magnitude of our estimate) for unpaid leave. Returning to our own estimates, the effect is even stronger for a return to the same job and job conditions, such as annual pay, weekly hours and leave rights. PPL can thus be considered successful in reaching its explicit goal of improving workplace attachment.

We repeat this comparison for three of the sample splits from Figure 3: high/low income, with/without tertiary qualification, and with/without employer-provided parental leave. We omit the self-employed, partnered/single and casual/other splits given the smaller sample size once we condition on having returned to work. Like the impact of PPL on the duration of leave, the improvement in job retention rates in the pre-birth job is concentrated among mothers without a tertiary qualification, in mothers without access to employer-funded parental leave, and to a lesser extent among low-income mothers. There is less heterogeneity in the PPL impact on the probability of not only returning to the same job, but also to the same conditions. For this outcome it is only access to employer-provided parental leave that

\footnotetext{
${ }^{27}$ As mentioned in Section 5.1, we test the robustness of our results using the uncensored sample of mothers who had their interview on or after the child's first birthday, instead of the full sample. Appendix A.6 shows very similar statistics for destination states (return to different types of jobs or no job) for the both samples. ${ }^{28}$ We find similar results if we repeat the analysis in Table 6 unconditional on having returned to any job. That is, 49 percent of all post-PPL mothers returned to the same job within one year versus 47 percent of all pre-PPL mothers, and 21 percent of all post-PPL mothers versus 18 percent of all pre-PPL mothers returned to the same job and same conditions within one year (see Appendix A.6).
} 
differentiates PPL impacts, with those not eligible for employer-provided leave displaying the larger PPL impacts.

$<$ Table 6 about here $>$

As discussed in Section 5.3.1., the scheme does have elements designed to maintain the prebirth job, but it has no characteristics which seem likely to influence the type of job taken up after parental leave if the pre-birth job is not maintained. However, if pre-PPL mothers and post-PPL mothers differ in their behavior not only because of access to PPL, but also because of changes to childcare costs over time, we would expect to see differences in the jobs they take up if they return. Specifically, post-PPL mothers should return to 'better' jobs than their pre-PPL counterparts on average, because they would be more likely to not return at all if the job is not good enough to justify high costs of alternative care provision.

Table 7 shows job characteristics of post-birth jobs, relative to pre-birth jobs, for both cohorts of mothers. There is no clear pattern in the impact of PPL on job characteristics that mothers accept upon return to work: both groups face the same reduction in pay, weekly working hours and occupational prestige, and the same changes in contract type. This result strongly suggests that changes in childcare costs had at worst a minor impact on post-PPL mothers' return behavior. Any potential bias in our estimates from this source should be minor.

Considering potential biases from differences in the labor market for both cohorts and any effects of the announcement of PPL on pre-PPL mothers, we interpret our results as a lower bound for the policy's true behavioral impact.

$<$ Table 7 about here $>$ 


\section{Conclusion}

This paper presents the first quantitative evidence on the labor supply and employment impacts of the Australian national PPL scheme introduced in January 2011. It makes a significant contribution to the growing international body of evidence on the impacts of parental leave schemes which is most important in three specific respects. First, the paper examines a reform that introduces a moderate leave period at moderate payment rates in an advanced industrialized country that did not previously have a universal paid parental leave scheme. These effects are likely to be different from the effects measured when existing leave entitlements, often of more than a year, are further extended. Evaluation of the Australian reform is of particular interest for countries where no (universal) leave scheme currently exists and where the introduction of one is being considered. In this respect the paper is unique in the recent literature. In addition, where similar paid parental leave schemes are already in place, the paper is suggestive of the labor supply benefits of maintaining such

schemes. Second, this paper is able to draw on rich data collected for the specific purpose of evaluating this policy which allows us to examine impacts on several labor market outcomes allowing for heterogeneous impacts across a wide range of mothers' characteristics. Few existing papers can do this, and none do so as extensively. Third, the paper adds to the small but growing group of existing studies internationally that have a credible identification strategy. However, a limitation of the paper is that we can only assess the impacts within the first year after childbirth.

We find that post-PPL mothers at first have a lower hazard rate for return to work than prePPL mothers, as they make use of the newly introduced paid leave that is now available to them. The hazard for post-PPL mothers then increases to overtake the counterfactual hazard. For example, some mothers who would have returned to work in months 1 to 3 in the absence of PPL now return in months 4 to 6. Depending on the exact statistical specification chosen, 
sometime between six and nine months, mothers with access to PPL are more likely to have returned to work than mothers without access to PPL. In this respect the impact of PPL appears in line with that found for earlier paid leave schemes elsewhere, such as the California Paid Family Leave scheme introduced in 2004 (Baum and Ruhm, 2016).

When we distinguish different subpopulations of women our results show clearly that lowincome mothers, mothers without tertiary education, and mothers without access to employer-funded parental leave respond more strongly to the introduction of PPL than highincome mothers, tertiary educated mothers and those with access to employer-funded leave. Such heterogeneous impacts have rarely been investigated in the literature on the labor market impacts of parental leave to date. Notable exceptions include Rossin-Slater, Ruhm and Waldfogel (2013) and Joseph et al. (2013), although neither study examines variation in impacts by eligibility for employer-funded leave, which we show here to be an important element of the overall picture on heterogeneous effects. Related to this, we also break new ground by demonstrating big differences in the impact of PPL by self-employment status. Ultimately our estimates offer strong support, and evidence for a particular causal mechanism (i.e. reducing the opportunity cost of delaying the return to work), for Rossin-Slater, Ruhm and Waldfogel's (2013) argument that paid leave schemes benefit disadvantaged groups of women more than other groups of women.

Among mothers who have returned to work by the time their child turns one year old, we show PPL has a significant positive impact on job continuity (keeping the pre-birth job at the pre-birth employer). This may be desirable from an efficiency point of view by limiting the loss of human capital. Existing evidence is somewhat mixed on this point, but our estimates are broadly in line with those of Baum and Ruhm (2016) when they widen the sample to include women who work fewer weeks during pregnancy. This positive job continuity impact is strongest for women without a tertiary qualification, without access to employer-funded 
leave, and for those with low income. This suggests that Rossin-Slater, Ruhm and Waldfogel's hypothesis on the impacts of paid leave vis-à-vis unpaid leave may extend to further outcomes of interest. We also find a positive impact on the probability of not only keeping one's pre-birth job, but also the same conditions. This effect does not appear to vary much across different groups of mothers. Overall, the policy is successful in helping mothers to balance paid work and family life, and to improve workplace attachment. Both effects are, on average, stronger among more disadvantaged groups.

A question that has arisen in the general debate in Australia given the modest duration and payment rate of PPL, is what would be the impact of increasing one of these or both. Guyonne Kalb (2018) reviewed the broader paid parental leave literature to assess the potential impact of increasing the generosity of the payment rate and the duration of the payment in Australia based on what we know from other countries. This literature suggests that the positive impacts observed after the introduction of PPL could be further extended. Kalb argues that Australia could extend the duration of its paid parental leave to up to one year without adverse consequences for women's labor market position. She also argues that increasing the payment rate in a well-designed parental leave policy can strengthen women's attachment to the labor market. 


\section{References}

Australian Bureau of Statistics (ABS). 2011a. Australian Social Trends Dec 2011. ABS Catalogue No. 4102.0, ABS, Canberra.

ABS. 2011b. Census Dictionary 2011. ABS Catalogue No. 2901.0, ABS, Canberra.

ABS. 2012. Gender Indicators, Australia, Jul 2012. ABS Catalogue No. 4125.0, ABS, Canberra.

ABS. 2013a. Labour Force, Australia, September 2013. ABS Catalogue No. 6202.0, ABS, Canberra.

ABS. 2013b. Consumer Price Index, Australia, June 2013. ABS Catalogue No. 6401.0, ABS, Canberra.

ABS. 2015. Average Weekly Earnings, Australia, May 2015. ABS Catalogue No. 6302.0, ABS, Canberra.

Bassford, Micaela and Hayley Fisher. 2016. "Bonus babies? The impact of paid parental leave on fertility intentions." Economics Working Paper Series 2016-04, Sydney: University of Sydney.

Baum, Charles L. 2003. "The Effect of Maternity Leave Legislations on Mothers' Labour Supply after Childbirth.” Southern Economic Journal 96(4): 772-799.

Baum, Charles L and Christopher J Ruhm. 2016. "The effects of paid family leave in California on labor market outcomes." Journal of Policy Analysis and Management 35(2): 333-356.

Baxter, Jennifer. 2009. "Mothers' Timing of Return to Work by Leave Use and Pre-Birth Job Characteristics." Journal of Family Studies 15(2): 153-166.

Baxter, Jennifer. 2013. "Parents Working Out Work." Australian Family Trends No. 1, Melbourne: Australian Institute of Family Studies.

Berger, Lawrence M and Jane Waldfogel. 2004. "Maternity Leave and the Employment of New Mothers in the United States." Journal of Population Economics 17(2): 331-349.

Buddelmeyer, Hielke, Mark Wooden and Suzan Ghantous. 2006. Transitions from Casual Employment in Australia. Report for Government. Melbourne Institute of Applied Economic and Social Research, available on https://melbourneinstitute.unimelb.edu.au/assets/documents/hildabibliography/other-publications/pre2010/Buddelmeyer_TransitionsfromCasualemployment.pdf .

Carneiro, Pedro, Katrine V Løken, and Kjell G Salvanes. 2010. "A Flying Start? Long-Term Consequences of Maternal Time Investments in Children during Their First Year of Life." IZA Discussion Paper No. 5362, Bonn: IZA.

Carneiro, Pedro, Katrine V Løken, and Kjell G Salvanes. 2015. "A Flying Start? Maternity Leave Benefits and Long-Run Outcomes of Children." Journal of Political Economy 123(2): $365-412$. 
Castro-García, Carmen and Maria Pazos-Moran. 2016. "Parental Leave Policy and Gender Equality in Europe". Feminist Economics 22(3): 51-74.

Dahl, Gordon B, Katrine V Løken, Magne Mogstad and Kari V Salvanes. 2016. "What is the case for paid maternity leave?" Review of Economics and Statistics 98(4): 655-670.

Han, Wen-Jui, Christopher J Ruhm, and Jane Waldfogel. 2009. "Parental Leave Policies and Parents' Employment and Leave-Taking." Journal of Policy Analysis and Management 28(1): 29-54.

Hanel, Barbara. 2013. "The Impact of Paid Maternity Leave Rights on Labour Market Outcomes." Economic Record 89(286): 339-366.

Human Rights and Equal Opportunity Commission. 2002. A Time To Value: Proposal For A National Paid Maternity Leave Scheme. https://www.humanrights.gov.au/our-work/sexdiscrimination/publications/time-value-proposal-national-paid-maternity-leave-scheme (accessed August 2018).

Jaumotte, Florence. 2003. "Labour force participation of women: empirical evidence on the role of policy and other determinants in OECD countries." OECD Economic Studies No. 37 2003/2: 51-108.

Joseph, Olivier, Ariane Pailhé, Isabelle Recotillet and Anne Solaz. 2013. "The economic impact of taking short parental leave: Evaluation of a French reform." Labour Economics 25C: $63-75$.

Kalb, Guyonne. (2018) Paid Parental Leave and Female Labour Supply: A Review, Economic Record, 94(304), 80-100.

Kalb, Guyonne. and Thor O Thoresen. 2010. "A comparison of family policy designs of Australia and Norway using microsimulation models." Review of Economics of the Household 8(2): 255-287.

Lalive, Rafael, Analía Schlosser, Andreas Steinhauer and Josef Zweimüller. 2014. "Parental leave and mothers' careers: The relative importance of job protection and cash benefits." Review of Economic Studies 81(1): 219-265.

Martin, Bill, Marian Baird, Michelle Brady, Barbara Broadway, Belinda Hewitt, Guyonne Kalb, Lyndall Strazdins, Wojtek Tomaszewski, Maria Zadoroznyj, Janeen Baxter, Rachael Chen, Meraiha Foley, Duncan McVicar, Gillian Whitehouse and Ning Xiang. 2015. PPL Evaluation Final Report. Canberra: Australian Government Department of Social Services.

Martin, Bill, Belinda Hewitt, Mara A Yerkes, Ning Xiang, Judith Rose and Laetitia Coles. 2014. Paid Parental Leave Evaluation, Phase 3 Report. Canberra: Australian Government Department of Social Services.

Productivity Commission. 2009. Paid Parental Leave: Support for Parents with Newborn Children. Report no. 47, Canberra.

Rønsen, Marit and Ragni Hege Kitterød. 2015. "Gender Equalizing Family Policies and Mothers' Entry into Paid Work: Recent Evidence from Norway." Feminist Economics 21(1): 59-89. 
Rønsen, Marit and Marianne Sundström. 2002. "Family policy and after-birth employment among new mothers - a comparison of Finland, Norway and Sweden." European Journal of Population 18(2): 121-152.

Rosenbaum, Paul R and Donald B Rubin. 1983. "The Central Role of the Propensity Score in Observational Studies for Causal Effects." Biometrika 70(1): 41-55.

Rosenbaum, Paul R and Donald B Rubin. 1985. "Constructing a Control Group Using Multivariate Matched Sampling Methods that Incorporate the Propensity Score." The American Statistician 39(1): 33-38.

Rossin-Slater, Maya. 2017. "Maternity and Family Leave Policy." IZA Discussion Paper No. 10500, Bonn: IZA.

Rossin-Slater, Maya, Christopher J Ruhm and Jane Waldfogel. 2013. "The Effects of California's Paid Family Leave Program on Mothers' Leave-Taking and Subsequent Labor Market Outcomes.” Journal of Policy Analysis and Management 32(2): 224-245.

Ruhm, Christopher J. 1998. "The Economic Consequences of Parental Leave Mandates: Lessons from Europe." The Quarterly Journal of Economics 113(1): 285-317.

Schönberg, Uta and Johannes Ludsteck. 2014. "Expansions in Maternity Leave Coverage and Mothers' Labor Market Outcomes after Childbirth." Journal of Labor Economics 32(3) (July 2014): 469-505.

Waldfogel, Jane, Yoshio Higuchi and Masahiro Abe. 1999. "Family leave policies and women's retention after childbirth: evidence from the United States, Britain, and Japan." Journal of Population Economics 12(4): 523-545.

\section{Acknowledgements}

This paper is based on commissioned research for the Australian Government Department of Social Services (DSS). We gratefully acknowledge funding by DSS and the opportunity to evaluate the newly introduced Paid Parental Leave. We also acknowledge support for Duncan McVicar's 2015 visit to Melbourne from the Visiting Research Scholar scheme of the Faculty of Business and Economics, University of Melbourne. Neither DSS nor the University of Melbourne are responsible for the views in this paper. We thank Katrien Stevens and participants at the 2015 Labour Econometrics Workshop in Sydney, the 2016 European Society for Population Economics Conference in Berlin, the 2016 Work and Family Researchers Network Conference in Washington DC, and seminars at the Tax and Transfer Policy Institute at the Australian National University, the Business School at the University of Western Australia, Queen's University Belfast, University College Dublin, the Economic and Social Research Institute, and Cardiff University for their helpful comments. The views expressed in this paper and any remaining errors are those of the authors solely. 
Table 1 Labor Market Outcomes before and after the introduction of PPL

\begin{tabular}{|c|c|c|c|c|}
\hline & pre-PPL & post-PPL & $\begin{array}{c}\text { Std. Err. } \\
\text { Of } \\
\text { Difference }\end{array}$ & \\
\hline \multicolumn{5}{|l|}{ Was observed to return to work after } \\
\hline$>13$ weeks and $<=18$ weeks & $5.7 \%$ & $8.0 \%$ & 0.006 & **** \\
\hline$>18$ weeks and $<=26$ weeks & $13.0 \%$ & $20.0 \%$ & 0.009 & **** \\
\hline$>26$ weeks and <= 39 weeks & $15.1 \%$ & $15.1 \%$ & 0.009 & \\
\hline$>39$ weeks and <= 52 weeks & $18.3 \%$ & $16.0 \%$ & 0.010 & * \\
\hline$>52$ weeks & $1.5 \%$ & $0.5 \%$ & 0.003 & $* * *$ \\
\hline An unknown period of time & $0.2 \%$ & $0.4 \%$ & 0.001 & \\
\hline Was not observed to return to work by last interview & $29.5 \%$ & $31.9 \%$ & 0.012 & * \\
\hline \multicolumn{5}{|l|}{ Was observed to return to work } \\
\hline $\begin{array}{l}\text { To the same job (employer and position) and conditions } \\
\text { did not change }\end{array}$ & $20.6 \%$ & $22.3 \%$ & 0.010 & \\
\hline $\begin{array}{l}\text { To the same job (employer and position) but conditions } \\
\text { did change }\end{array}$ & $32.0 \%$ & $30.3 \%$ & 0.012 & \\
\hline To a different job (employer and/or position) & $17.8 \%$ & $15.4 \%$ & 0.009 & ** \\
\hline To an unknown job & $0.1 \%$ & $0.2 \%$ & 0.001 & \\
\hline Was not observed to return to work by last interview & $29.5 \%$ & $31.9 \%$ & 0.012 & * \\
\hline \# of observations & 2587 & 4201 & & \\
\hline
\end{tabular}


Table 2 Socioeconomic characteristics before and after the introduction of PPL

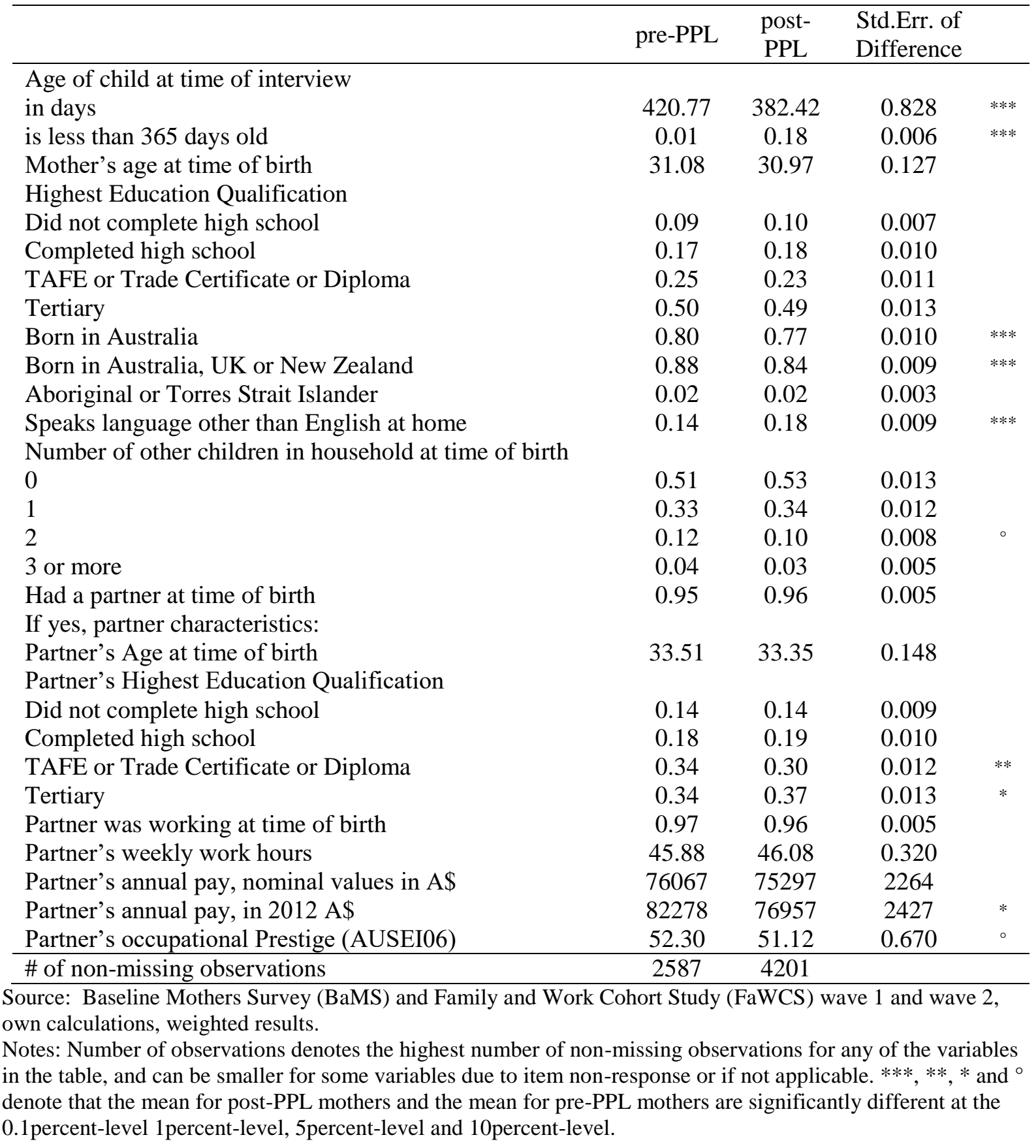


Table 3 Pre-birth job characteristics before and after the introduction of PPL

All mothers

\begin{tabular}{|c|c|c|c|c|}
\hline \multirow[b]{2}{*}{ Sector } & \multirow[t]{2}{*}{ Pre-PPL } & \multirow[t]{2}{*}{ Post-PPL } & \multicolumn{2}{|c|}{$\begin{array}{l}\text { Std. Err. Of } \\
\text { Difference }\end{array}$} \\
\hline & & & & \\
\hline Private, for profit & 0.62 & 0.65 & 0.012 & $* *$ \\
\hline Private, not for profit & 0.08 & 0.08 & 0.007 & \\
\hline Government business/enterprise & 0.06 & 0.05 & 0.006 & \\
\hline Government & 0.24 & 0.21 & 0.011 & * \\
\hline \multicolumn{5}{|l|}{ Firm size } \\
\hline $0-20$ & 0.22 & 0.22 & 0.011 & \\
\hline $21-100$ & 0.13 & 0.16 & 0.009 & ** \\
\hline$>100$ & 0.65 & 0.62 & 0.012 & * \\
\hline Was employee & 0.93 & 0.94 & 0.006 & $*$ \\
\hline \multicolumn{5}{|l|}{ If employee: } \\
\hline Had problems with employer during pregnancy & 0.15 & 0.14 & 0.009 & \\
\hline $\begin{array}{l}\text { Received support from employer during } \\
\text { pregnancy }\end{array}$ & 0.60 & 0.57 & 0.012 & ** \\
\hline \multicolumn{5}{|l|}{ Contract type } \\
\hline Permanent ongoing & 0.81 & 0.81 & 0.010 & \\
\hline Fixed-term & 0.06 & 0.07 & 0.006 & \\
\hline Casual & 0.13 & 0.12 & 0.009 & \\
\hline Other & 0.00 & 0.01 & 0.002 & \\
\hline Weekly work hours & 33.50 & 34.12 & 0.315 & * \\
\hline Annual pay, nominal value in $\mathrm{A} \$$ & 56997 & 50780 & 3988 & \\
\hline Annual pay, in $2012 \mathrm{~A} \$$ & 61652 & 51899 & 4310 & $\circ$ \\
\hline Occupational Prestige (AUSEI06) & 59.19 & 56.95 & 0.558 & $* * *$ \\
\hline \multicolumn{5}{|l|}{ Industry } \\
\hline Female dominated industry & 0.66 & 0.65 & 0.012 & \\
\hline Agriculture, Forestry and Fishing & 0.02 & 0.01 & 0.003 & $*$ \\
\hline Mining & 0.01 & 0.01 & 0.003 & \\
\hline Manufacturing & 0.03 & 0.03 & 0.004 & \\
\hline Electricity, Gas, Water and Waste Service & 0.02 & 0.01 & 0.003 & * \\
\hline Construction & 0.02 & 0.03 & 0.004 & \\
\hline Wholesale Trade & 0.02 & 0.02 & 0.003 & \\
\hline Retail Trade & 0.11 & 0.12 & 0.008 & \\
\hline Accommodation and Food Service & 0.04 & 0.05 & 0.005 & \\
\hline Transport, Postal and Warehousing & 0.02 & 0.02 & 0.004 & \\
\hline Information Media and Telecommunication & 0.04 & 0.03 & 0.004 & \\
\hline Financial and Insurance Services & 0.10 & 0.09 & 0.007 & \\
\hline Rental, Hiring and Real Estate Services & 0.02 & 0.01 & 0.003 & \\
\hline Professional, Scientific and Technical & 0.04 & 0.09 & 0.006 & $* * *$ \\
\hline Administrative and Support Services & 0.03 & 0.08 & 0.005 & $* * *$ \\
\hline
\end{tabular}


All mothers

\begin{tabular}{lcccc}
\hline & Pre-PPL & Post-PPL & \multicolumn{2}{c}{$\begin{array}{c}\text { Std. Err. Of } \\
\text { Difference }\end{array}$} \\
\hline Public Administration and Safety & 0.06 & 0.05 & 0.006 & $*$ \\
Education and Training & 0.13 & 0.11 & 0.008 & $*$ \\
Health Care and Social Assistance & 0.24 & 0.20 & 0.011 & $* * *$ \\
Arts and Recreation Services & 0.03 & 0.02 & 0.004 & $*$ \\
Other services & 0.03 & 0.03 & 0.004 & \\
Other & 0.00 & 0.01 & 0.002 & $* * *$ \\
\hline \# of observations & 2587 & 4201 & & \\
\# of non-missing observations & 2582 & 4197 & & \\
\hline
\end{tabular}

Source: Baseline Mothers Survey (BaMS) and Family and Work Cohort Study (FaWCS) wave 1 and wave 2, own calculations, weighted results.

Notes: Number of non-missing observations denotes the highest number of non-missing observations for any of the variables in the table, and can be smaller for some variables due to item non-response or if not applicable. $* * *, * *, *$ and ${ }^{\circ}$ denote that the mean for post-PPL mothers and the mean for pre-PPL mothers are significantly different at the $0.1 \%$-level $1 \%$-level, $5 \%$-level and $10 \%$-level. 
Table 4 Survivor function of remaining out of work at selected durations from birth Kaplan Meier estimate

\begin{tabular}{|c|c|c|c|c|c|}
\hline & Treated & Untreated & Diff. & $\begin{array}{l}\text { Std. Err. of } \\
\text { Difference }\end{array}$ & \\
\hline 13 weeks & 0.92 & 0.85 & 0.07 & 0.009 & $* * *$ \\
\hline 18 weeks & 0.85 & 0.78 & 0.07 & 0.010 & $* * *$ \\
\hline 26 weeks & 0.64 & 0.65 & -0.01 & 0.012 & \\
\hline 39 weeks & 0.47 & 0.50 & -0.03 & 0.013 & \\
\hline 52 weeks & 0.27 & 0.32 & -0.05 & 0.013 & $* *$ \\
\hline \# observations & 3,981 & 2,554 & & & \\
\hline $\begin{array}{l}\text { Source: Baseline M } \\
\text { own calculations. } \\
\text { Notes: } * * *, * * \text { and } * \\
5 \%-l e v e l \text { respectivel } \\
\text { treated mothers) we } \\
\text { recorded return date }\end{array}$ & $\begin{array}{l}\text { Survey ( } \\
\text { te gaps in } \\
\text { t of the to } \\
\text { nmed in th } \\
\text { nor prior }\end{array}$ & $\begin{array}{l}\text { and Family } \\
\text { al rates that at } \\
\text { imber of } 6,78 \\
\text { ching proced } \\
\text { first day at ris }\end{array}$ & $\begin{array}{l}\text { ork Co } \\
\text { tically } \\
\text { cuation } \\
\text { urther }\end{array}$ & $\begin{array}{l}\text { dy (FaWCS) } \\
\text { ant at the } 0.1 \% \\
\text { rvations were }\end{array}$ & $\begin{array}{l}\% \text {-le } \\
\text { ons }\end{array}$ \\
\hline
\end{tabular}




\begin{tabular}{|c|c|c|c|c|c|}
\hline \multirow{4}{*}{$\begin{array}{l}\text { Baseline effect of PPL } \\
\text { Log-Likelihood }\end{array}$} & \multicolumn{5}{|c|}{ Effect of PPL is constant } \\
\hline & \multirow{3}{*}{$\begin{array}{c}\text { Coeff. } \\
0.083\end{array}$} & \multirow{2}{*}{$\begin{array}{l}\text { Std. } \\
\text { Err. } \\
0.031\end{array}$} & \multirow{2}{*}{$\begin{array}{c}\begin{array}{c}\mathrm{Z}- \\
\text { value }\end{array} \\
2.68\end{array}$} & \multicolumn{2}{|l|}{$\begin{array}{c}\mathrm{p}- \\
\text { value }\end{array}$} \\
\hline & & & & 0.007 & $* *$ \\
\hline & & \multicolumn{2}{|c|}{-37266.190} & & \\
\hline & \multicolumn{5}{|c|}{$\begin{array}{l}\text { Effect of PPL changes over time } \\
\text { (linear) }\end{array}$} \\
\hline & Coeff. & $\begin{array}{l}\text { Std. } \\
\text { Err. }\end{array}$ & $\begin{array}{c}\mathrm{Z}- \\
\text { value }\end{array}$ & $\begin{array}{c}\mathrm{p}- \\
\text { value }\end{array}$ & \\
\hline Baseline effect of PPL & -0.287 & 0.071 & -4.07 & 0.000 & $* * *$ \\
\hline interacted with days since birth (in 100s of days) & 0.184 & 0.031 & 5.94 & 0.000 & $* * *$ \\
\hline \multirow{3}{*}{ Log-Likelihood } & \multicolumn{5}{|c|}{-37247.818} \\
\hline & \multicolumn{5}{|c|}{$\begin{array}{l}\text { Effect of PPL changes over time } \\
\text { (quadratic) }\end{array}$} \\
\hline & Coeff. & $\begin{array}{l}\text { Std. } \\
\text { Err. }\end{array}$ & $\begin{array}{c}\mathrm{Z}- \\
\text { value }\end{array}$ & $\begin{array}{c}\mathrm{p}- \\
\text { value }\end{array}$ & \\
\hline \multirow{3}{*}{$\begin{array}{l}\text { Baseline effect of PPL } \\
\text { interacted with days since birth (in 100s of days) } \\
\text { interacted with days since birth (in 100s of days, squared) } \\
\quad()\end{array}$} & -0.822 & 0.122 & -6.73 & 0.000 & $* * *$ \\
\hline & 0.880 & 0.131 & 6.73 & 0.000 & $* * *$ \\
\hline & 0.173 & 0.031 & -5.54 & 0.000 & $* * *$ \\
\hline Log-Likelihood & \multicolumn{5}{|c|}{-37231.42} \\
\hline \# observations & \multicolumn{5}{|c|}{6535} \\
\hline \multicolumn{6}{|c|}{$\begin{array}{l}\text { Source: Baseline Mothers Survey (BaMS) and Family and Work Cohort Study (FaWCS) wave } 1 \text { and wave } 2 \text {, } \\
\text { own calculations. } \\
\text { Notes: } * * *, * * * \text { and }{ }^{\circ} \text { denote whether the coefficients are significant at the } 0.1 \% \text {-level } 1 \% \text {-level, } 5 \% \text {-level and } \\
10 \%-\text {-level. Standard errors are robust. See notes to Table } 4 \text { for a description of observations that were excluded } \\
\text { from the sample. }\end{array}$} \\
\hline
\end{tabular}


Table 6 The impact of PPL on returning to same job and same conditions

\begin{tabular}{|c|c|c|c|c|}
\hline & Treated & $\begin{array}{l}\text { Control: } \\
\text { Matched }\end{array}$ & $\begin{array}{l}\text { Std.Err. of } \\
\text { Difference }\end{array}$ & \\
\hline Returned to same job & 0.78 & 0.74 & 0.014 & $* *$ \\
\hline $\begin{array}{l}\text { Returned to same job and conditions (hours, salary } \\
\text { etc.) }\end{array}$ & 0.34 & 0.28 & 0.015 & $* * *$ \\
\hline \multicolumn{5}{|l|}{ Returned to same job } \\
\hline High Education & 0.78 & 0.77 & 0.019 & \\
\hline Low Education & 0.78 & 0.70 & 0.021 & $* * *$ \\
\hline High Income & 0.77 & 0.74 & 0.026 & \\
\hline Low Income & 0.79 & 0.74 & 0.046 & $\circ$ \\
\hline Has employer-paid leave & 0.79 & 0.80 & 0.021 & \\
\hline Does not have employer-paid leave & 0.76 & 0.70 & 0.019 & $* *$ \\
\hline \multicolumn{5}{|l|}{ Returned to same conditions (hours, salary etc.) } \\
\hline High Education & 0.33 & 0.28 & 0.021 & $*$ \\
\hline Low Education & 0.35 & 0.29 & 0.023 & $* *$ \\
\hline High Income & 0.26 & 0.22 & 0.026 & \\
\hline Low Income & 0.41 & 0.35 & 0.055 & $\circ$ \\
\hline Has employer-paid leave & 0.34 & 0.29 & 0.024 & $\circ$ \\
\hline Does not have employer-paid leave & 0.34 & 0.28 & 0.020 & $*$ \\
\hline \# observations & 2,517 & 1,655 & & \\
\hline \multicolumn{5}{|c|}{$\begin{array}{l}\text { Source: Baseline Mothers Survey (BaMS) and Family and Work Cohort Study (FaWCS) wave } 1 \text { and wave } 2 \text {, } \\
\text { own calculations. } \\
\text { Notes: } * * * * * * \text { and }{ }^{\circ} \text { denote that the mean for post-PPL mothers and the mean for pre-PPL mothers are } \\
\text { significantly different at the } 0.1 \% \text {-level } 1 \% \text {-level, } 5 \% \text {-level and } 10 \% \text {-level. Standard errors are robust. From the } \\
\text { total sample of } 6,788 \text { mothers, a return to work by the baby's first birthday had been recorded for } 4,319 \text { mothers. } \\
5 \% \text { of post-PPL mothers with the highest propensity score were trimmed (144 observations). }\end{array}$} \\
\hline
\end{tabular}


Table 7: The impact of PPL on job characteristics - mothers who return to work and have changed job conditions

\begin{tabular}{|c|c|c|c|}
\hline & Treated & $\begin{array}{l}\text { Control: } \\
\text { Matched }\end{array}$ & $\begin{array}{l}\text { Std.Err. of } \\
\text { Difference }\end{array}$ \\
\hline \multicolumn{4}{|l|}{ Contract type } \\
\hline Changed from permanent to non-permanent & 0.21 & 0.21 & 0.017 \\
\hline Changed from non-permanent to permanent & 0.03 & 0.03 & 0.008 \\
\hline Change in average hours & -15.68 & -14.81 & 0.516 \\
\hline Change in median Annual Pay (2012 A\$) & -18562.65 & -17264.39 & 985.40 \\
\hline Median relative change in Annual Pay (2012 A\$) & $-39 \%$ & $-37 \%$ & 0.020 \\
\hline Change in average Occupational Prestige (0-100) & -0.54 & -0.58 & 0.374 \\
\hline \# observations & 1,558 & 1,054 & \\
\hline \multicolumn{4}{|c|}{$\begin{array}{l}\text { Source: Baseline Mothers Survey (BaMS) and Family and Work Cohort Study (FaWCS) wave } 1 \text { and wave } 2 \text {, } \\
\text { own calculations. } \\
\text { Notes: } * * *, * * * \text { and }{ }^{\circ} \text { denote that the mean (median) for post-PPL mothers and the mean (median) for pre-PPL } \\
\text { mothers are significantly different at the } 0.1 \% \text {-level } 1 \% \text {-level, } 5 \% \text {-level and } 10 \% \text {-level. Standard errors are robust } \\
\text { In the total sample of } 6,788 \text { mothers, a return to work by the baby's first birthday and a change of jobs or job } \\
\text { conditions was recorded for } 2,932 \text { mothers. Observations with missing information on the dependent variable } \\
\text { were dropped, ranging from zero to } 239 \text { dropped observations (for annual pay and contract type respectively) } \\
\text { Finally, the 5\% of post-PPL mothers with the highest propensity score were trimmed. The number of observations } \\
\text { reported in the table refers to the smallest final sample size. }\end{array}$} \\
\hline
\end{tabular}


Figure 1 Distribution of propensity scores

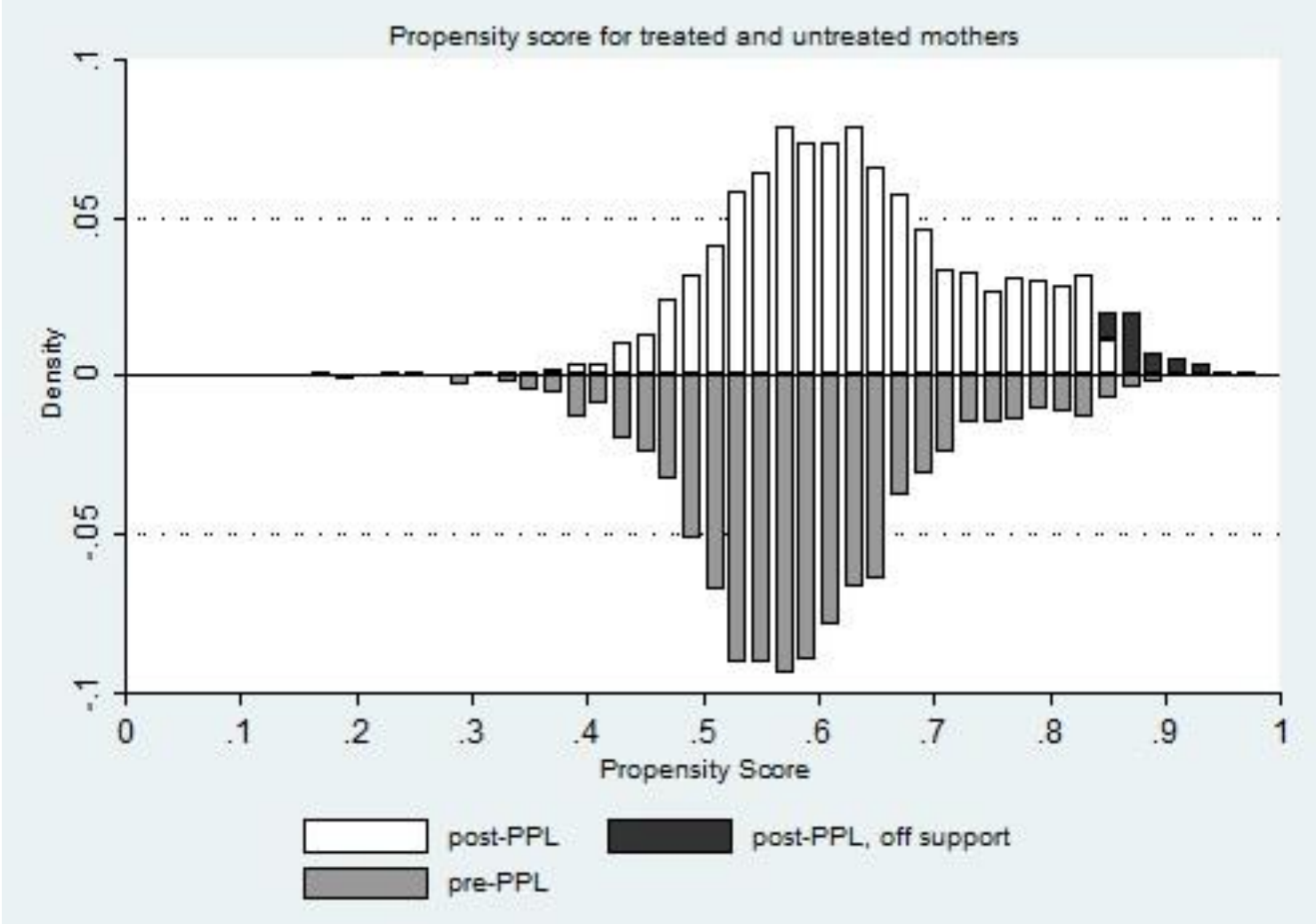

Source: Baseline Mothers Survey (BaMS) and Family and Work Cohort Study (FaWCS) wave 1 and wave 2, own calculations. 
Figure 2 Survivor function of being out of work by access to PPL - Kaplan Meier estimate

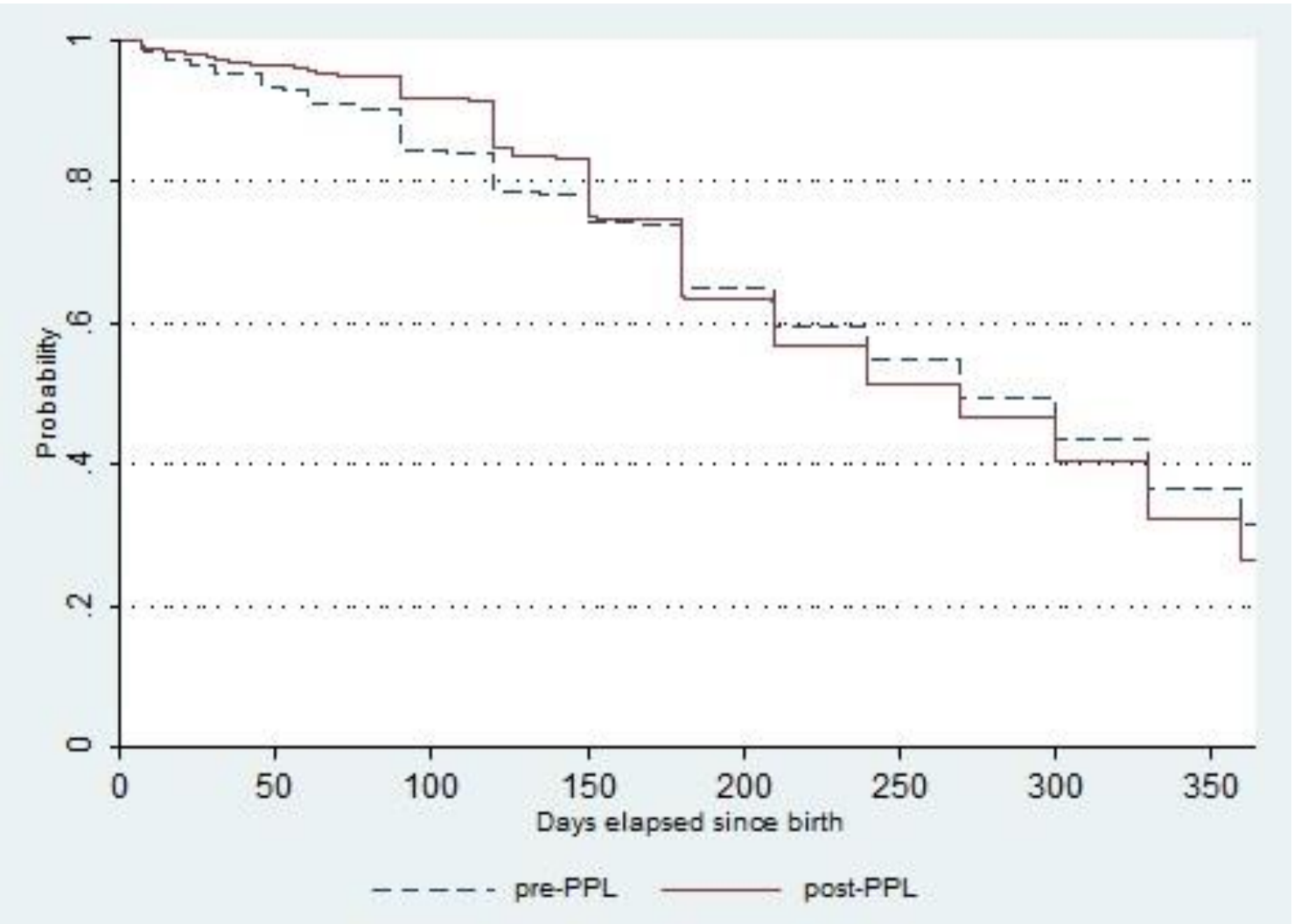

Source: Baseline Mothers Survey (BaMS) and Family and Work Cohort Study (FaWCS) wave 1 and wave 2, own calculations. 
Figure 3 Survivor function for being out of work by access to PPL - Kaplan Meier estimate by subgroups

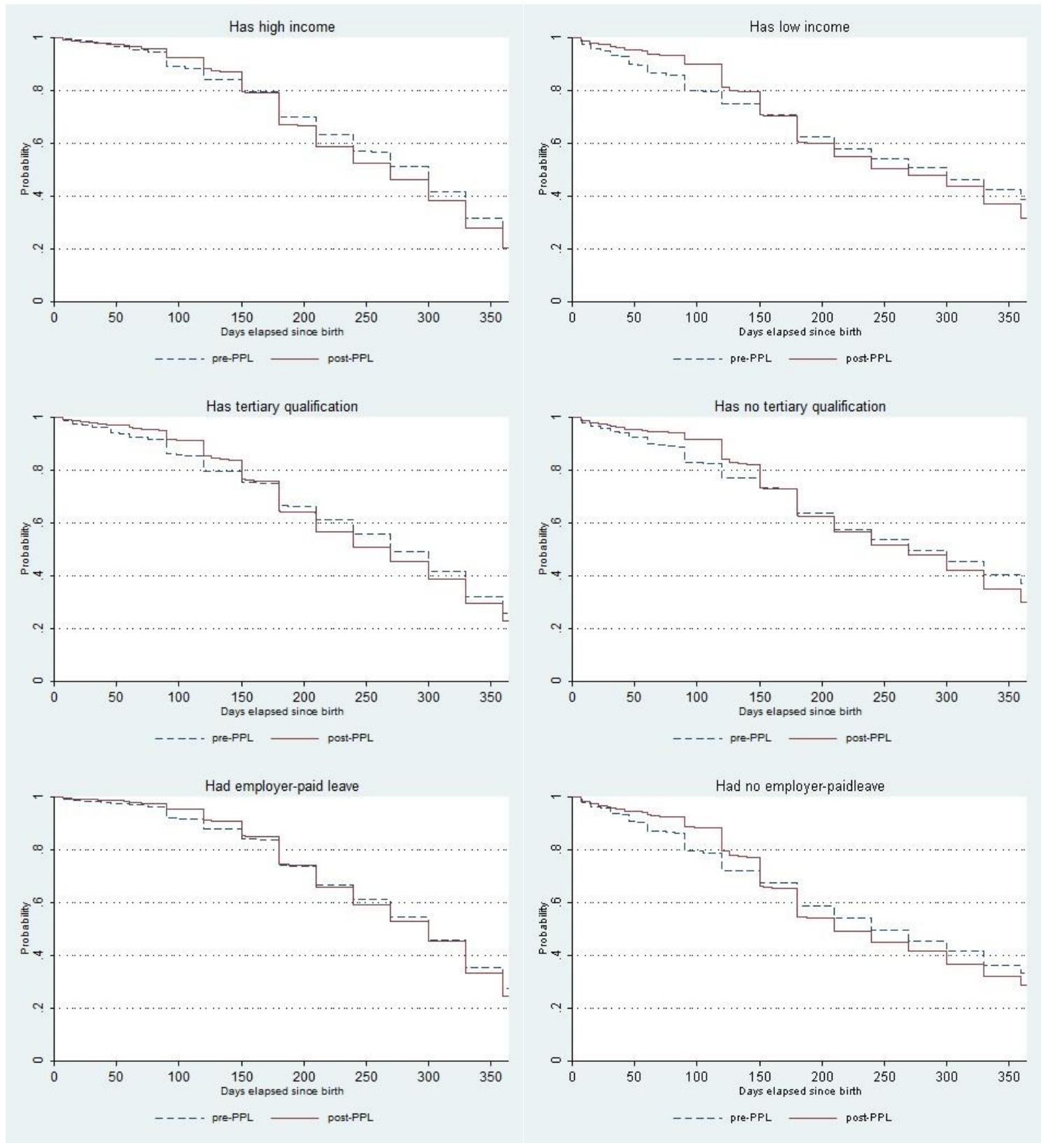




\section{Figure 3 - continued}

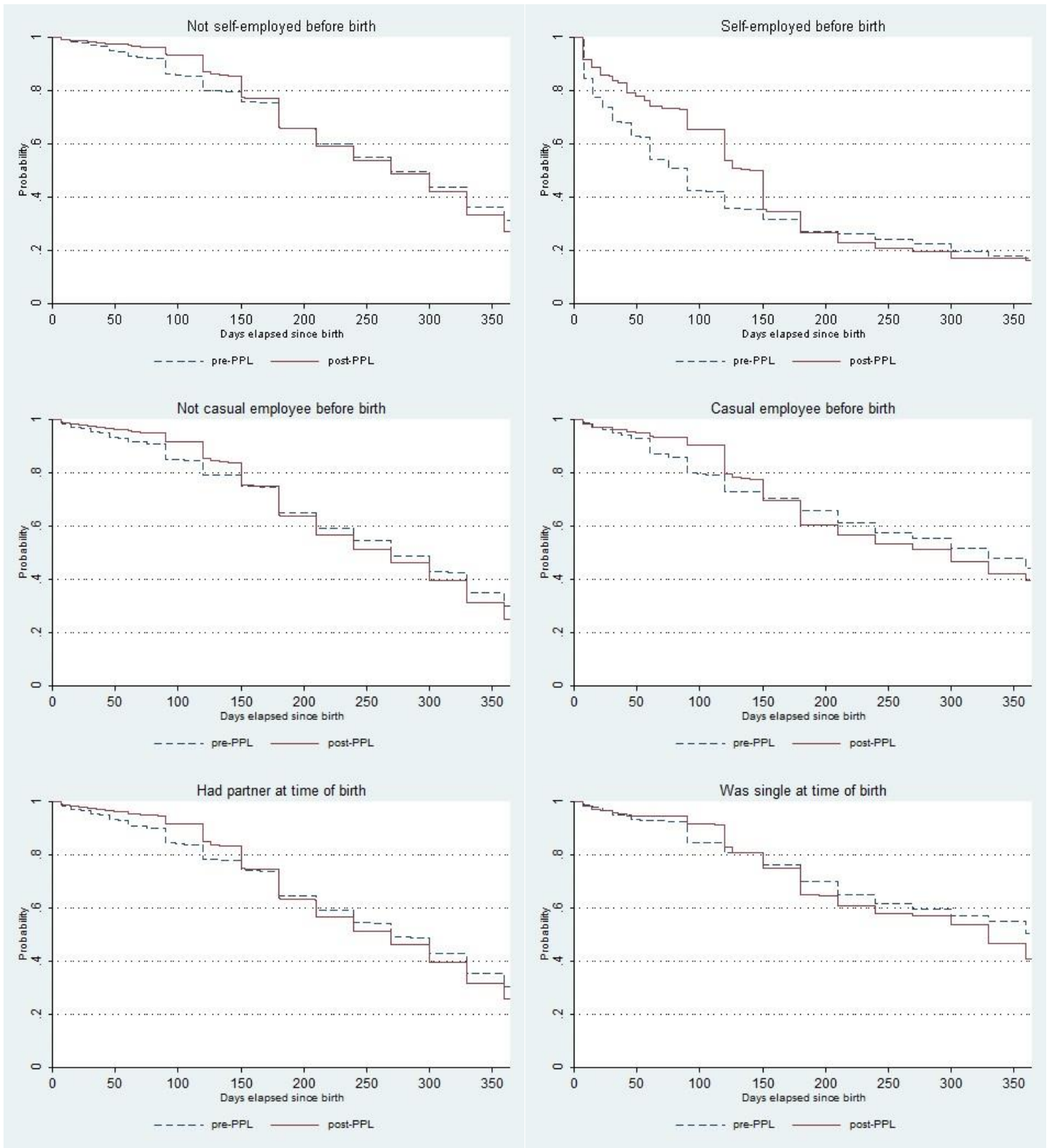

Source: Baseline Mothers Survey (BaMS) and Family and Work Cohort Study (FaWCS) wave 1 and wave 2, own calculations. 